\title{
Why bread in the diet lowers serum cholesterol
}

\section{By J. J. Groen, Department of Psychobiological Research, University of Leiden, felgersma-Kliniek, Oegstgeest, The Netherlands}

This paper will deal exclusively with the relationship between diet and serum cholesterol level. Many publications have appeared in which the role of diet in the production of atherosclerosis and ischaemic heart disease has been discussed. However, in these discussions it is often not sufficiently realized that ischaemic heart disease is a condition of multifactorial origin and that diet and serum cholesterol level are only one of the several factors which influence its prevalence, incidence and effect on mortality rates.

As a further restriction this paper will deal only with experience in the human. In this respect two main methods have been used to elucidate the effect of different dietary factors on the serum cholesterol level. Different diets have been given to healthy human volunteers and in-patients, and as a result of this work it is now agreed that certain nutrients, especially saturated fats, cholesterol and sucrose (when taken in excessive amounts), increase the serum cholesterol level. There is less unanimity of opinion about the role of other dietary factors. Several investigators have shown that when saturated fat in the diet is replaced isoenergetically by polyunsaturated fat the serum cholesterol level is reduced; monounsaturated fat has a similar effect but it is less pronounced. From these observations, it has been concluded that polyunsaturated fat has a specific effect in lowering the serum cholesterol.

Other authors have confirmed these observations but have found in control experiments that when saturated fat is replaced by foodstuffs like bread, rice or oats, the serum cholesterol level is also lowered. In their opinion therefore dietary saturated fat has the specific effect of increasing the serum cholesterol level; the replacement of saturated fat by almost all other nutrients (and not specifically by polyunsaturated fat) merely reduces the serum cholesterol level to its physiologically normal level.

A second approach in assessing the role of dietary factors in determining the serum cholesterol level has been the use of what may be called nutritional epidemiology. This method compares the serum cholesterol levels of certain population groups who eat different diets, and attempts to correlate differences in serum cholesterol levels with certain factors in the diet. In this respect special attention has been given to population groups which are distinguished by low average serum cholesterol levels, because these groups also have low frequencies of ischaemic heart disease. It is therefore of great medical importance to identify the factors which are responsible for these low serum cholesterol values. I have been able to examine three such 
groups, namely Trappist monks in Holland (Groen, Tijong, Koster, Willebrands, Verdonck \& Pierloot, 1962), Yemenite Jews (Groen, Balogh \& Yaron, I966) and Arab Bedouin (Groen, Balogh, Levy, Yaron, Zemach \& Benaderet, I964) in Israel. The mean serum cholesterol levels in the age group 40-70 years in these people was respectively $(\mathrm{g} / \mathrm{l}) \mathrm{r} \cdot 80, \mathrm{r} \cdot 65$ and $\mathrm{r} \cdot 50$. Table $\mathrm{I}$ shows a comparison of the mean intake of foodstuffs $(\mathrm{g} / \mathrm{d})$ in the three populations compared with the composition of an average Western diet. This table also shows values for the analytical composition of their diets.

Table I. Comparison of the composition $(g / d)$ of an average 'Western', Trappist monks', Yemenite and a Bedouin diet

(Values in parentheses indicate the energy content $(\%))$

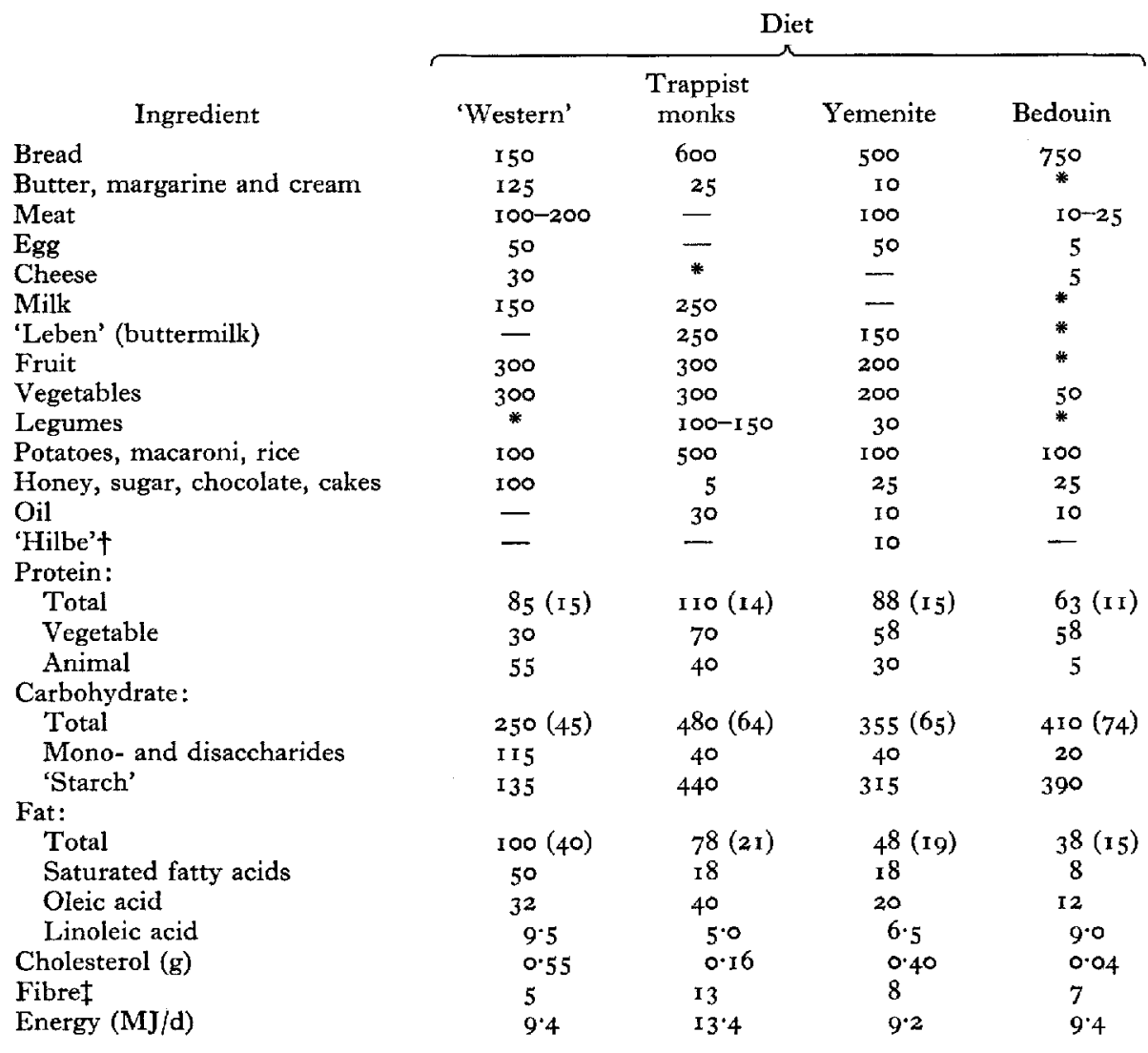

*These ingredients were not always included in the diet. †Spice prepared from fenugreek (Prigonella foenungracum). †Approximate values.

A number of dietary factors may be responsible for the low serum cholesterol levels in all three groups. Factors common to all three, compared with the Western diet, are first the higher intake of carbohydrates and the lower intakes of fat and cholesterol than in the Western diet. On closer examination it is obvious that 
within the carbohydrate group the consumption of starch is considerably higher, but the quantities of mono- and disaccuarides are lower than in the Western diet. This is due to the large quantities of sucrose eaten by Western populations.

With respect to fat consumption, not only are the total quantities of dietary fat lower in the three groups but the amount of saturated fat is particularly low. There is little difference in oleic acid consumption between the Western diet and the 'Trappists' diet, but the Yemenites and Bedouin consume less of this monounsaturated fatty acid. None of the three low-serum-cholesterol groups consume a particularly high amount of linoleic acid. This important finding of the epidemiological study is often neglected by Western nutritionists who are inclined, through their work with volunteers, to believe that a high intake of polyunsaturated fat is the necessary condition for a low serum cholesterol level. This was not shown in our studies or in those of other workers. It is too often forgotten that oils rich in polyunsaturated fat, e.g. safflower, sunflower-seed, soya-bean and maize oils have only recently become available for human nutrition. It was only after the modern processes of industrial steam distillation were introduced that these oils could be offered for human consumption because in their crude state their taste was unacceptable. There is no population group, at least not to my knowledge, which uses such oils as natural foodstuffs. Populations such as the Bedouin or the Yemenites consume most of their polyunsaturated fat in the form of wheat-germ oil which is present in the high-extraction flour from which they bake their bread. In other population groups polyunsaturated fat is obtained from sunflower seed or maize. However, eating these products in their natural state as staple foods rarely provides more than $5^{-10} \mathrm{~g}$ linoleic acid/d. This quantity is much less than the amounts usually given to volunteers in Western nutritional experiments.

Our study of the diets of the three low-cholesterol groups, therefore, does not support the wide-spread popular belief that a high intake of polyunsaturated fat is a necessary condition for the maintainance of a low serum cholesterol level. This holds only when one wants to lower the serum cholesterol level while maintaining a high fat consumption. This is only possible by substituting the saturated fat by unsaturated fats. However, 'natural' population groups which are characterized by a lower mean serum cholesterol level subsist on quite different diets: their diet is low in total fat and consequently also in saturated fat. The energy supplied in Western diets by saturated fat is obtained in the diets of population groups with low serum cholesterol levels by high intakes of polysaccharides and vegetable protein. I am not aware of any exception to this rule. This high intake of polysaccharides and vegetable protein, replacing saturated fat, was derived in our study from bread. The Trappist monks had, in addition, a very high intake of peas and beans of which they ate up to $150 \mathrm{~g} / \mathrm{d}$. A high intake of these legumes is also found in some Middle-Eastern groups where fava beans (Vicia faba) are an important ingredient of the diet. However, the simplest hypothesis which emerges from these epidemiological studies is that replacement of saturated fat by bread in the diet lowers serum cholesterol levels just as efficiently as replacement by polyunsaturated fat in the studies with individual subjects. 
To test this hypothesis fifteen normal human non-Yemenite volunteers first ate a Western diet of the type reproduced in Table $\mathbf{I}$. After 5 weeks on this diet during which the mean serum cholesterol level remained stable at a value of about $2 \cdot 15 \mathrm{~g} / 1$, they transferred to the Yemenite diet shown in Table $\mathbf{I}$. This included some ingredients which are unusual in the West, e.g. sweet potatoes, the typical spice of 'hilbe' (prepared from fenugreek) and the national drink 'gizer' prepared from the skin of coffee beans. There was a fast reduction in the serum cholesterol level to a mean value of about $\mathrm{I} \cdot 73 \mathrm{~g} / 1$; in some of the younger volunteers values were below I.50 $\mathrm{g} / \mathrm{l}$. This indicated that the low serum cholesterol level in the Yemenites was not an ethnic or genetic characteristic: when Western volunteers ate the Yemenite diet their serum cholesterol level decreased to the same low 'Yemenite' level. The results also showed that diet was the main factor in lowering serum cholesterol levels, because during the experiment the Western volunteers, mostly medical personnel, continued to live a Western way of life. When they returned to the Western diet their serum cholesterol level returned to its previous high level (Fig. I).

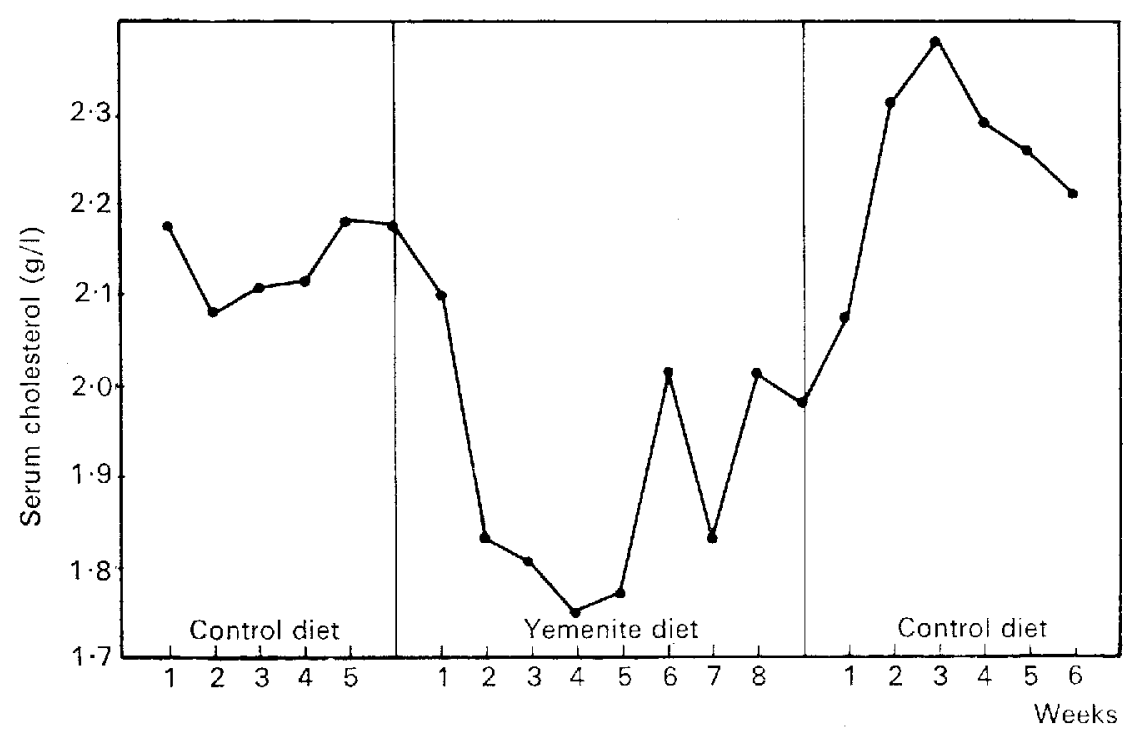

Fig. I. Mean weekly serum cholesterol levels of ten healthy volunteers given a control or Yemenite diet for periods of 5 weeks (for details of dicts see p. 161 ).

After this experiment was concluded four of the volunteers continued on another experiment in which, after another control period on the Western diet, they consumed a 'therapeutic' diet. This was composed of completely Western ingredients but was prepared with the same quantities of animal and vegetable protein, polysaccharides and the same low-fat content as the Yemenite diet. The bread was prepared from $72 \%$-extraction flour. The results are shown in Fig. 2. In all volunteers eating this 'imitation' Yemenite diet the serum cholesterol level decreased to the same value as that found with the 'real' Yemenite diet. This result indicated that the 


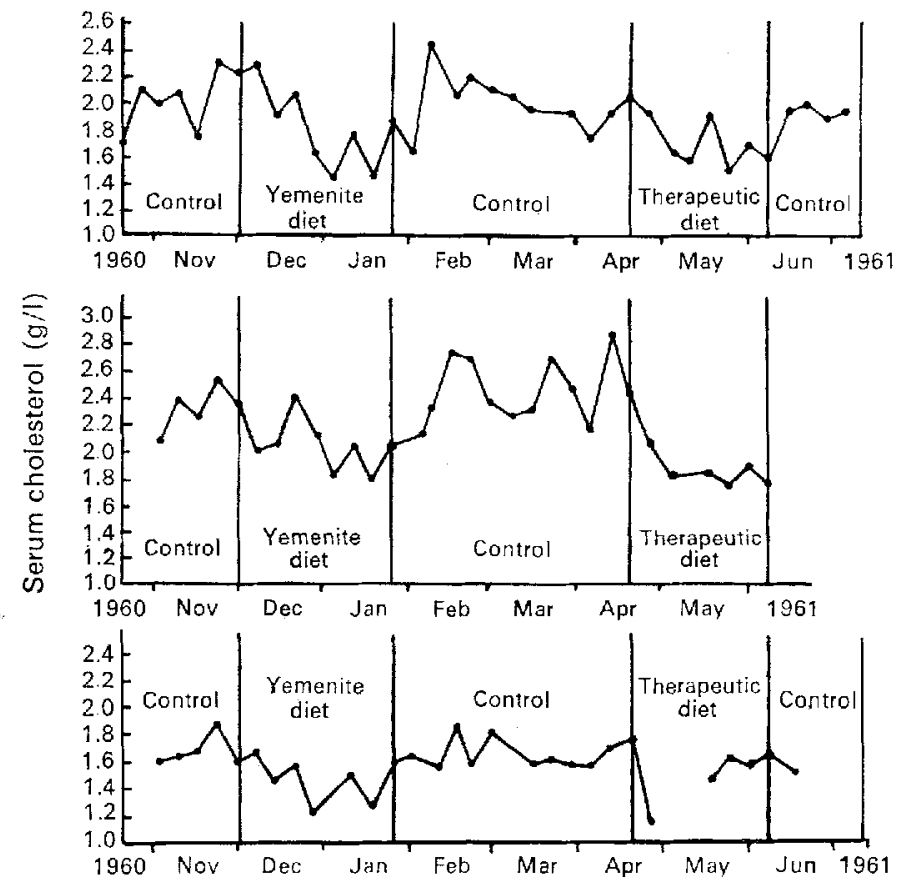

Fig. 2. Serum cholestcrol levels of three voluntecrs given a control diet for 5 weeks followed by a Yemenite diet, a further control period, then a therapeutic diet which was composed of Western ingredients, prepared with the same quantitics of animal and vegetable protcin, polysaccharides and fat as the Yemenite diet (for further details of diets see p. I62).

low serum cholesterol level found in the Yemenites was not a result of the presence of typical spices as had been suspected by some but to the composition of the diet, characterized by low total and saturated fat and a high intake of starch and vegetable protein. This was achieved mainly by a high consumption of bread, of which the male volunteers ate $400 \mathrm{~g} / \mathrm{d}$ and the women about $300 \mathrm{~g} / \mathrm{d}$.

I must confess that at that time we were not considering fibre as a possible factor which might be responsible for the low serum cholesterol levels in the three groups we examined. Table I shows that the fibre content of the Western diet is indeed lower than that of the three other groups; also, most of the fibre in the Western diet is derived from vegetables and fruits but in the other groups it was mainly derived from bread and, in the instance of the Trappist monks, additionally from peas and beans. In retrospect, however, the result of the second experiment, in which white bread was eaten, suggests that it was not the fibre intake which was responsible for the low serum cholesterol level but the starch and the protein in the bread which isoenergetically replaced saturated fat. In the light of recent hypotheses, particularly those of Trowell (1972a,b), it is acknowledged, however, that our experiment should be repeated with diets high in white bread, with and without added bran. Recently Eastwood and his co-workers (Eastwood, I969; Eastwood, Hamilton, 
Kirkpatrick \& Mitchell, I973) reported similar experiments which produced apparently negative results.

We then investigated the reason for the reduction of serum cholesterol levels when bread is contained in the diet, and whether this is due to the starch or the protein of the bread. It is too often forgotten that bread, especially among populations with a high consumption, contributes considerable quantities of protein to the diet. The average protein content of bread is $9 \%$. To investigate any difference in the capacity between wheat starch and wheat protein to lower the serum cholesterol levels, we studied two groups of human volunteers. After a control period (period I) on a Western diet both groups received diets in which saturated fat was isoenergetically replaced by bread. In the first group (A) this bread was prepared from flour to which had been added one-third of its weight of wheat starch; in the second group (B) the bread was prepared from flour to which had been added one-third of its weight of wheat gluten. Half of the intake of this 'enriched' bread was prepared from $85 \%$-extraction flour and half from $72 \%$ extraction flour. Therefore, both diets had the same fibre content but in one diet (diet I) the saturated fat was replaced mostly by starch and in the other it was replaced by gluten (diet 2). Both diets contained the same low amounts of total and saturated fats, sucrose and cholesterol; the quantities of polyunsaturated fats were the same. Total protein content was also the same in both diets but the volunteers who ate the starch bread (group $A$ ) received their protein mostly from lean meat and skim milk; those who ate the gluten bread (group B) received their dietary protein mainly as wheat protein. In view of the well-known variation in individual responses to changes in diet, each diet was given to two groups of subjects and after the first experimental period (period 2) of 5 weeks, each of two groups received the other diet for the second 5-week period (period 3) (Groen, 1967).

The effects of the two types of diets on the mean serum cholesterol levels in the two groups of volunteers are shown in Fig. 3. As in the previous experiments, the

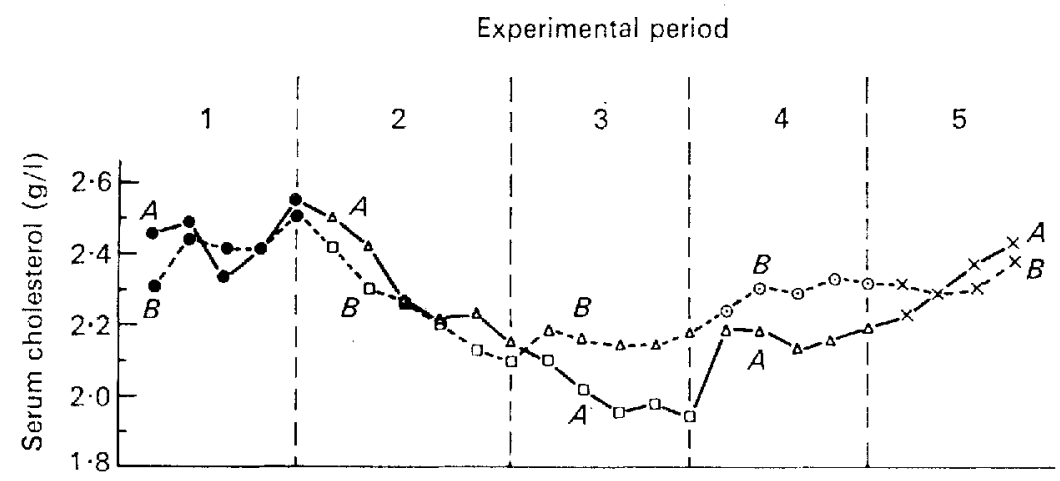

Fig. 3. Serum cholesterol levels in two groups (A and B) of volunteers given bread diets supplemented with starch or gluten and containing either animal or vegetable protein, for periods of 5 weeks (for experimental details see above). $\bullet$, High-fat diet, $A$, Starch-bread dict (high animal protein); $\square$, Gluten-bread diet (high vegetable protein); 0 , High-sugar diet (high animal protein); $\times$, Self chosen diet. 
transfer from a Western diet to either of the low-fat diets produced a marked and progressive decrease in the serum cholesterol levels in both groups. There was no difference between the levels in the group given the gluten-supplemented bread diet and the one given the starch-supplemented bread diet. However, during the second experimental period, when each of the groups were given the other diet, a significant difference appeared: in the group (A) now receiving the gluten-supplemented bread diet, the serum cholesterol level continued to decrease compared with that recorded in the previous period; in the group (B) that changed from the gluten- to the starch-supplemented bread, there was no further change. Also, when in the next experimental period (period 4 ) group A returned to the starch-animalprotein diet, there was a significant increase in their mean serum cholesterol. Therefore the results obtained in the first experimental period (period 2) seemed to suggest that the nature of the protein in the diet did not influence the serum cholesterol level, the results from the next period (period 3) suggested that there was a change in levels associated with the nature of the protein.

In view of these contradictory results, it seems premature to offer a conclusion; there may have been several reasons for the difference in the response of the serum cholesterol levels to the diets in the two groups of volunteers. It is well known that there are considerable variations in the patterns of response to the same diet among different individuals.

The influence of the nature of the carbohydrate was again demonstrated in period 4 of the experiment; when the volunteers of group B were transferred from the starch-supplemented bread diet to a diet of the same composition in which the starch was largely replaced by sucrose, the mean serum cholesterol levels increased by $0.16 \mathrm{~g} / 1(0.05<P<0.10)$.

It must be concluded, therefore, that the influence of bread on the serum cholesterol levels, when it replaces saturated fat in the diet, can now be regarded as established; whether gluten and starch have an equal share in this effect needs further investigation. A role for fibre cannot be excluded but as the fibre content of both types of bread was low, this role does not seem very important, and is certainly less important than that of either starch or gluten. The results of experiments done by Ahrends, Hirsch, Insull, Tsaltas, Blomstrand \& Peterson (1957) who found large reductions in serum cholesterol levels in human volunteers given diets containing only polyunsaturated fat, casein and D-maltose, without any fibre, and the work of Eastwood (1969) and Eastwood et al. (1973) indicate that dietary fibre is not an important regulator of serum cholesterol levels.

The effects of different carbohydrates and proteins on the amount of serum lipids in animals and men have been reviewed by several authors (Portman \& Stare, I959; MacDonald, I964; Hodges \& Krehl, 1965; Hodges, 1966) and the importance of other staple foods e.g. rice (Starke, 1950), oats (de Groot, Luyken \& Pikaar, I963), legumes (Luyken, Pikar, Polman \& Schippers, 1962), and potatoes (Grande, Anderson \& Keys, 1965) has also been studied. The knowledge of these effects is of practical interest because there is evidence that a long protracted increase in serum cholesterol levels is a factor in the multicausal pathogenesis of coronary heart 
disease. A diet which will keep the serum cholesterol levels low has become an important part of the therapy and prevention of this condition. Based on the evidence that the substitution of saturated fatty acids with polyunsaturated fatty acids in the diet lowers the serum cholesterol level, the American Heart Association ( $196 \mathrm{I}$ ) has advised the public to eat less saturated fat, and to increase the intake of vegetable oils. It was not mentioned in these recommendations that substitution of saturated fat with non-fat nutrients can produce the same result, and this advice, although of course justified, is, therefore, somewhat one-sided. In particular, both the epidemiological evidence and the experiments with volunteers leave no doubt that diets low in saturated fats and sugar, but with a high content of bread, can also produce very low serum cholesterol levels. As bread is also a source of protein, vitamin-B complex, and essential fatty acids, and has an important role in the nutrition of the populations of developing countries, the omission of a recommendation to substitute saturated fat by bread is to be regretted.

In the United States of America, saturated fat is consumed in large amounts and the majority of the population will probably resist any advice to substitute saturated fat with non-fat nutrients. In most of the so-called developing countries, however, the regular diets are relatively low in fat but there is an increasing tendency to substitute bread and other staple foods with sucrose. This may explain why workers from the Western hemisphere are inclined to attach more importance to the type of fat in the diet but those from other countries consider the type of staple food more important in the dietary regulation of cholesterolaemia. In the field of nutrition both aspects of the composition of the diet are equally worth studying, particularly as we have at present only a vague knowledge of the biochemical processes by which saturated fatty acids exert their influence on the serum cholesterol level. These mechanisms may act in the absorption, synthesis, metabolism or excretion of cholestcrol or its metabolites, and they need not be the same for the different classes of nutrients. Recently we found that when saturated fat in the diet is replaced by polyunsaturated fat or by bread, the reduction in serum cholesterol levels is accompanied by an increased excretion of neutral steroids and bile acids in the stools.

The author is indebted to the Editor of the American Journal of Clinical Nutrition for permission to reproduce tables and figures from a previous publication. 'The work reported was supported by National Heart Institute Grant H-4427 and by grants from the Netherlands Association of Four Millers and the Netherlands Organization for Nutrition and Food Research (T.N.O.).

\section{REFERENCES}

Ahrends, E. H., Hirsch, J., Insull, W., Tsaltas, T. T., Blomstrand, R. \& Peterson, M. C. (1957). Lancet i, 943 .

American Heart Association (1961). Circulation 23, 133.

de Groot, A. P., Luyken, R. \& Pikaar, N. A. (1963). Lancet ii, 303.

Eastwood, M. A. (1969). Lancet ii, r222.

Fastwood, M. A., Hamilton, T., Kirkpatrick, J. R. \& Mitchell, W. D. (1973). Proc. Nutr. Soc. 32, 22A.

Grande ,F. J. T., Anderson, J. T. \& Keys, A. (1965). F. Nutr, 86, 313.

Groen, J. J. (1967). Am. \%. clin. Nutr. 20, 19г. 
Groen, J. J., Balogh, M., Levy, M., Yaron, E., Zemach, R. \& Benaderet, S. (1964). Am. \%. clin. Nutr. I4, 37 .

Groen, J. J., Balogh, M. \& Yaron, E. (г966). Israel F. med. Sci. 2, 196.

Groen, J. J., Tijong, K. B., Koster, M., Willebrands, A. F., Verdonck, G. \& Pierloot, M. (ig62). Am. 7. clin. Nutr. 10, $45^{6}$.

Hodges, R. E. \& Krehl, W. A. (1965). Am. Y. clin. Nutr. r7, 334.

Hodges, R. E. (1966). Nutr. Abstr. Rev. 24, 65.

Keys, A., Anderson, J. T. \& Grande, F. (I960). F. Nutr. 70, 257.

Luyken, R., Pikaar, N. A., Polman, H. \& Schippers, F. (I962). Voeding 23, 447.

MacDonald, I. (I 964). Nutr. Abstr. Rev. 22, 257.

Portman, O. W. \& Stare, F. J. (I959). Physiol. Rev. 39, 407.

Starke, H. (1950). Am. F. Med. 9, 494.

Trowell, H. (1972a). Revue Elud. clin. biol. 17, 345 .

Trowell, H. (1972b). Am. F. clin. Nutr. 25, 926 . 